\author{
Cadernos de \\ ESTUDOS LINGǘlSTICOS - (54.1), Campinas, Jan./Jun. 2012
}

\title{
UMA VISÃO ENUNCIATIVO-DISCURSIVA \\ DA HESITAÇÃO
}

\author{
JULYANA CHAVES NASCIMENTO1
}

\section{RESUMO}

Este artigo realiza uma reflexão sobre a hesitação. Para tanto, retomamos o modo como esse fenômeno tem sido tratado na literatura linguística brasileira e constatamos uma lacuna no que diz respeito à investigação da hesitação de uma perspectiva lingüístico-discursiva. Com o objetivo de apresentar tal visão sobre a hesitação, abordamos conceitos advindos de estudos da psicanálise lacaniana, bem como do discurso e da enunciação: o dialogismo - formulado no círculo de Bakhtin -, o interdiscurso desenvolvido na Análise do Discurso de linha francesa - e as heterogeneidades enunciativas -, conforme a proposta de Authier-Revuz. Com base na análise de um fragmento de conversação, propomos que a hesitação constitui um acontecimento que indicia a negociação do sujeito com outros constitutivos do discurso/do sujeito. Argumentamos, ainda, que a representação da hesitação no discurso constitui indício de deriva e de ancoragem, denunciando quão problemático é, para o sujeito, o estabelecimento de fronteiras do/no discurso. Esperamos com esta reflexão lançar luz sobre a investigação da hesitação como um fenômeno de natureza lingüístico-discursiva. Ambicionamos, inclusive, instigar pesquisas com esse viés teórico e contribuir para preencher o que constatamos como uma lacuna nos estudos brasileiros sobre hesitação.

Palavras-Chave: hesitação, discurso

\begin{abstract}
We will brainstorm and deliberate upon the matter of hesitation, starting with a recall of the way this phenomenon has been approached in Brazilian linguistic literature. As a matter of fact, there is some sort of emptiness regarding the analysis of hesitation, based on a linguistic-discursive perspective. In order to support our beliefs regarding this topic, we gathered some concepts from studies of Lacanian psychoanalysis, of discourse analysis and enunciation: dialogism - formulated in the Bakhtin circle -; the interdiscourse - developed in Discourse Analysis of the French line -; and enunciation's heterogeneity - as proposed by Authier-Revuz. Based on the analysis of a dialogue extract, we presume that hesitation is a process of deal-making with the other constitutive of discourse and subject. We also consider that hesitation is constituted of drifting and anchoring processes. As the main goal of our deliberation, we seek to break the barriers of investigation, raising it to a linguistic - discursive level. We also expect to instigate researches on this theoretical bias, to start filling one gap in the Brazilian studies about hesitation.
\end{abstract}

Keywords: hesitation, discourse

${ }^{1 .}$ IBILCE/UNESP. Marília (SP), Brasil. e.mail: julyana.chaves.nascimento@gmail.com. 


\section{APRESENTAÇÃO}

Neste artigo, abordamos a hesitação. Propomos uma reflexão teórica sobre esse fenômeno da linguagem. Para tanto, analisamos, num primeiro momento, como ele tem sido tratado na perspectiva da textual-interativa (MARCUSCHI, 1998 e 2006; BARROS, 1999). Essa, que será uma retomada breve do modo como predominantemente, no Brasil, se tem estudado a hesitação, visa permitir que o leitor calcule a distância entre a proposta teórica que aqui apresentaremos e propostas já consolidadas por estudos linguísticos brasileiros. Na sequência, destacaremos conceitos advindos de estudos do discurso e da enunciação. Baseados numa releitura da proposta sobre heterogeneidades enunciativas de Authier-Revuz $(1990,2004)$, faremos uma retomada de formulações do círculo de Bakhtin, da Análise do Discurso de linha francesa (AD) e da psicanálise lacaniana. Esses conceitos se constituem um caminho que julgamos necessário para a compreensão do que entendemos como hesitação. Portanto, tais conceitos constituem a base teórica sobre a qual alicerçamos a proposta de que a hesitação é um acontecimento discursivo. Por fim, expomos aspectos que tomamos como definidores da hesitação, o que faremos com base na análise de um recorte de situação enunciativo-discursiva.

Convém destacar o fato de que a concepção que defendemos é fruto de nossa inserção no Grupo de Pesquisa Estudos sobre a linguagem (GPEL/CNPq), coordenado pelo prof. Dr. Lourenço Chacon ${ }^{2}$. No interior deste Grupo de Pesquisa, essa concepção vem sendo construída ao longo dos últimos dez anos e, embora sua formalização atual guarde certo ineditismo, não a pretendemos completa ou imutável.

\section{A HESITAÇÃO NOS ESTUDOS DE ABORDAGEMCONVERSACIONAL}

Segundo a ótica textual-interativa (MARCUSCHI, 2006), as hesitações ${ }^{3}$ desempenham papéis que podem ser vistos sob três ângulos: formal, cognitivo e interacional. Indissociáveis da fala, as marcas de hesitação exerceriam funções importantes na realização e na manutenção da atividade conversacional. Dentre as marcas linguísticas que caracterizam a hesitação, Marcuschi (1998) destaca: repetição de palavras de pequeno porte, pausas (preenchidas ou não) e alongamentos de vogais, consoantes ou sílabas. Para esse autor, as marcas de hesitação atuam no plano da formulação textual, e não se encontram aleatoriamente distribuídas, já que obedecem a princípios de distribuição e servem como indicação de organização sintagmática da língua.

2. UNESP - Faculdade de Filosofia e Ciências - Departamento de Fonoaudiologia.

3. É esta a expressão utilizada por Marcuschi. Preferimos, no entanto, interpretar a hesitação como marcas de hesitação, uma vez que, na formulação do autor, não há diferenciação explícita entre o fenômeno da hesitação e as marcas com que esse fenômeno se mostra no texto conversacional. 
Como se pode observar nas considerações de Marcuschi (a propósito, um dos mais representativos dessa tradição em relação ao fenômeno hesitação), as marcas de hesitação são caracterizadas como marcas linguísticas que colaborariam para a organização conversacional e/ou como marcas linguísticas que evidenciariam o processo de formulação conversacional. No que se refere, mais especificamente, a seu papel na organização conversacional, Marcuschi (1990) destaca que, na construção colaborativa de sentido - a atividade de compreensão -, é necessário voltar a atenção para uma tarefa comum e sinalizá-la, tarefa que, segundo o autor, seria marcada por hesitação. Desse modo, as marcas de hesitação funcionariam como: sinalizadores que viabilizam tarefas de construção do sentido; sinalizadores de conclusão, solicitação, consentimento e permissão de tomada de turno; e, ainda, marcadores de limites tópicos.

Barros (1999) destaca que as marcas de hesitação seriam delatoras de processos mais específicos da conversação (processos de formulação do texto conversacional). Nessa perspectiva, marcas de hesitação como pausas e prolongamentos de vogais (dentre outros) assegurariam ao falante o tempo e o meio linguístico necessários à formulação e à reformulação da fala. Desse modo, podemos dizer que a ocorrência de marcas de hesitação explicitaria o esforço do falante em formular sua fala, bem como o de lidar com problemas que ocorrem no que poderia ser entendido, nessa visão, como processamento verbal e cognitivo.

As marcas de hesitação são, nos estudos acima referidos, consideradas como fenômenos característicos da atividade interacional/conversacional. Destaquemos que a perspectiva textual-interativa contribuiu para que a hesitação passasse a ser vista como fenômeno sistemático e necessário à interação verbal, ao invés de ser observada como índice de uma situação problema ou de disfluência (em seu sentido mais negativo).

Os trabalhos sobre hesitação apresentados até aqui certamente contribuíram para alicerçar nossa reflexão. Entretanto, julgamos que há outras possibilidades interpretativas para o funcionamento desse fenômeno linguístico. $\mathrm{O}$ deslocamento que aqui propomos teve como alicerce estudos de natureza enunciativo-discursiva, os quais nos possibilitaram pensar a hesitação, privilegiadamente, como um acontecimento discursivo ${ }^{4}$. Alguns dos pressupostos teóricos que permitiram esse deslocamento são apresentados a seguir.

\section{PRESSUPOSTOS TEÓRICOS PARA UMA VISÃO ENUNCIATIVO DISCURSIVA DA HESITAÇÃO}

Circunscrever conceitos que vêm possibilitando a construção de outra visão sobre a hesitação é, a nosso ver, necessário, senão essencial. Conforme adiantamos, este é um caminho que consideramos como fundamental para que o

\footnotetext{
${ }^{4}$. Tomamos o termo "acontecimento" no sentido de "um fato novo" que, em seu contexto de atualidade, convoca uma memória que já começa a se reorganizar (PÊCHEUX, 2008).
} 
leitor acompanhe nossa proposta de que a hesitação constitui um acontecimento discursivo cujas marcas são indício da negociação, problemática, do sujeito com os outros constitutivos do (seu) discurso.

Inspiramo-nos essencialmente na proposta das "Heterogeneidades enunciativas" de Authier-Revuz (1990). A autora põe em evidência a problemática do dialogismo do círculo de Bakhtin e do discurso como produto do interdiscurso, bem como a abordagem do sujeito e de sua relação com a linguagem permitida pela psicanálise (freudiana e lacaniana). Cada uma dessas perspectivas de estudo a respeito da heterogeneidade do sujeito/da linguagem mostrou-se fundamental para o que propomos em termos do entendimento da hesitação. Por isso, seguindo o percurso de Authier-Revuz (1990), destacamos aspectos que têm contribuído para compor nossa concepção sobre esse fenômeno. Buscamos, nesse percurso, situar a hesitação em relação ao que Authier-Revuz denomina de heterogeneidade constitutiva do discurso e de heterogeneidade mostrada no discurso.

No que se refere à problemática do dialogismo do círculo de Bakhtin, presente nas reflexões dessa autora, baseamo-nos na idéia de que "nossos enunciados estão repletos de palavras dos outros, caracterizadas, em graus variáveis, pela alteridade ou pela assimilação, caracterizadas também, em graus variáveis, por um emprego consciente e decalcado" (BAKHTIN, 2000, p. 314). É em torno da caracterização do enunciado que procuramos explorar a relação dessa perspectiva com a hesitação. Dois são os aspectos que colocamos em evidência para a definição do enunciado: o primeiro o relacionado à situação enunciativa, e o segundo a outros enunciados.

$O$ primeiro aspecto que define o enunciado se refere a sua condição de unidade real da comunicação verbal. Conforme Bakhtin (2000), as unidades da língua (por exemplo, as orações), na medida em que são mobilizadas por um locutor em uma situação enunciativa determinada, constituiriam enunciados. No entanto, para o autor, o sentido de um enunciado não pode, de modo algum, fazer referência somente às unidades verbais das orações: ele deve remeter, necessariamente, ao contexto no qual essas unidades são mobilizadas, e, portanto, à alternância de sujeitos. Destaquemos, desse primeiro aspecto que caracteriza o enunciado, que seus limites são definidos pela alternância dos sujeitos falantes numa situação enunciativa.

O outro aspecto definidor do enunciado é o vínculo que mantém com outros enunciados, ou seja, o fato de que "cada enunciado é um elo da cadeia muito complexa de outros enunciados" (BAKHTIN, 2000, p. 291). Essa cadeia pressupõe a própria língua usada pelo locutor. Segundo Bakhtin (2000), as palavras do sistema linguístico não são apresentadas ao locutor como tiradas de um dicionário, uma vez que a linguagem não mais conserva formas ou palavras neutras que não pertencem a ninguém; para o autor, a palavra está sempre carregada de um sentido ideológico ou vivencial. É, assim, habitada pelo já-dito dos outros contextos nos quais viveu sua existência, que a língua chega ao sujeito falante. Além da própria língua, as palavras dos outros, das quais nossos enunciados estariam repletos, pressupõem enunciados anteriores (do próprio locutor ou de outro) aos quais cada enunciado está vinculado. Desse modo, o locutor não seria o Adão que nomeia pela primeira vez objetos ainda não designados, Adão mítico que poderia 
Cadernos de Estudos Lingǘisticos (54.1) - Jan./Jun. 2012

ter escapado à orientação dialógica inevitável do já-dito/já-ouvido da palavra do outro. Destaquemos, desse segundo aspecto que define o enunciado, sua orientação dialógica fundamental e inevitável.

O dialogismo do círculo de Bakhtin (conforme a denominação de AuthierRevuz, [1990]), marcado, dentre outros, por esses dois aspectos da definição do enunciado, influenciou nossa concepção sobre a hesitação. Conceber, então, a hesitação como um acontecimento relacionado ao processo de negociação com os outros - o próprio interlocutor da situação enunciativa e com os outros enunciados a que enunciados "proferidos" estão vinculados - torna-se possível a partir do postulado de que todo enunciado, definido numa situação enunciativa pela alternância de sujeitos falantes, é fundamental e inevitavelmente constituído pelas palavras dos outros. Entendemos que as marcas da hesitação conferem a esses outros certo grau de visibilidade, na medida em que constituiriam indícios da existência desses outros. Assim, da perspectiva do dialogismo fundamental e inevitável da linguagem, a hesitação constitui um acontecimento discursivo cujas marcas são indício do processo de constituição do discurso. Além disso, com base na afirmação de Bakhtin de que as palavras que constituem nossos enunciados podem ser caracterizadas, em graus variáveis, por um emprego consciente e decalcado, supomos que as marcas da hesitação são indícios do processo de constituição do sujeito.

A problemática do discurso como produto do interdiscurso - conforme proposta pela Análise do Discurso, especialmente por Pêcheux (1997-a, 1997b, 2008) -, também contribuiu para dar contorno a nossa concepção sobre a hesitação. Eis como se deu a atuação dessa problemática sobre o modo como concebemos a hesitação.

Baseada em reflexões de Althusser e de Foucault sobre a existência histórica e material das ideologias, a análise do discurso estabelece, segundo Courtine (1999), um já discurso determinando o assujeitamento do sujeito falante à ordem do discurso. A existência do enunciado que molda o discurso estaria ligada, segundo o mesmo autor, à noção de repetição, no sentido de séries de formulações, ou seja, de enunciações distintas e dispersas articuladas entre si em formas linguísticas determinadas (citando-se, repetindo-se, parafraseando-se, opondo-se entre si, transformando-se). Esse espaço vertical, estratificado e desnivelado dos discursos, a que Courtine (1999) denomina de interdiscurso, constitui a exterioridade do enunciável para o sujeito enunciador, lugar dos pré-construídos dos quais sua enunciação se apropria.

À semelhança do que propõe a teoria da enunciação de filiação bakhtiniana, a Análise do Discurso entende que o funcionamento do discurso não é integralmente linguístico (verbal). Existiria uma instância ideológica responsável pelo assujeitamento do sujeito, ou seja, uma instância responsável por fazer o sujeito acreditar que é fonte de seu discurso e que está exercendo sua livre vontade. Entretanto, esse sujeito seria suporte e efeito de um discurso regulado do exterior, ou seja, do interdiscurso.

Destacamos, desse breve desdobramento da problemática do discurso como produto do interdiscurso, a determinação do discurso e do sujeito, de algo que 
se poderia entender como seu exterior. Ou seja, o discurso se caracteriza por um funcionamento consciente/pré-consciente que tem a característica de colocar o dito e, em consequência, rejeitar o não dito; ele se caracteriza, ainda, por um processo de natureza inconsciente, que consiste na interpelação, pela ideologia, dos indivíduos em sujeitos falantes fontes de seu dizer, ou pelo assujeitamento do sujeito como sujeito ideológico. Recortada dessa forma, a perspectiva do discurso como produto do interdiscurso nos permitiu compreender que as marcas da hesitação, já vistas como indício do processo de constituição do discurso, constituem indício da colocação ${ }^{5}$ de fronteiras entre o selecionado e o rejeitado. Além disso, pudemos, a partir dessa proposta da análise do discurso, reafirmar a suposição de que a hesitação constitui um acontecimento relacionado ao processo de constituição do sujeito, uma vez que as marcas da hesitação indiciariam a interpelação-assujeitamento que constitui o sujeito ideológico.

A proposição da análise do discurso sobre o assujeitamento do sujeito à ordem do discurso como um processo inconsciente nos remete ao que, para Freud e Lacan, seria o processo de constituição do sujeito e de sua relação com a linguagem. Atentos ao fato de que também nossa remissão à psicanálise se deve a Authier-Revuz (1990), vejamos fragmentos dessa concepção de sujeito e de sua relação com o modo como vimos concebendo a hesitação.

Contrariamente à imagem de um sujeito pleno, causa primeira e autônoma de uma palavra homogênea, a psicanálise - especificamente aquela representada pelas leituras lacanianas de Freud - trata o sujeito como efeito de linguagem. Segundo Tfouni (1998), é o impedimento da permanência do indivíduo num estado fusional com a mãe - estado de plenitude e em decorrência do qual não se precisaria falar -, ou seja, é a interdição que cria uma proibição fundamental, a de que não é possível não ser falante. A interdição resulta numa estrutura complexa na qual o sujeito barrado, descentrado, cindido - dotado de inconsciente, ou seja, de uma instância ${ }^{6}$ que, segundo Authier-Revuz (2004), é portadora de conflitos esquecidos, recalcados, eventualmente portadores de sofrimentos e que agem na vida presente sem que o sujeito saiba - recria para si, no fantasmagórico, a ilusão de um centro.

Nessa perspectiva, o sujeito não é uma entidade homogênea exterior à linguagem, mas efeito de linguagem. Para além da consciência - relativa ao $\mathrm{Ego}^{7}$ -, o sujeito, constitutivamente dividido, é assujeitado ao inconsciente. Para esse sujeito dividido, só há centro na ilusão:

\footnotetext{
5. Esta “colocação" seria consciente/pré-consciente, conforme destaca Pêcheux, mas, também, inconsciente, na medida em que, conforme destacaremos mais à frente, os conteúdos inconscientes agem na vida do sujeito sem que ele se dê conta dessa ação.

6. Lembremos, também, que o inconsciente seria uma região constituída a partir do desenvolvimento do aparelho psíquico (composto por id, ego e superego), no modelo de Freud. "É efeito do mecanismo de defesa do ego, [o recalque]" (FERRAZ e FERRAZ, 2001, p. 23)

7. Essa noção de Ego, e de outras instâncias psíquicas, é extraída de um recorte do modelo estrutural e funcional do psiquismo idealizado por Freud. Cf. Ferraz e Ferraz (2001).
} 
o eu [sujeito linguístico], por sua natureza propriamente imaginária (...) é titular de uma função essencial: função de desconhecimento. Desconhecimento da verdade que torna possível o saber; desconhecimento em que o sujeito organiza sua vida como um território em que ele sabe poder encontrar referências em suas imagens, território que ele não sabe ser uma toca; desconhecimento que, aplicado ao sujeito coletivo, pode tomar o nome de ideologia (CLÉMENT, 1973 apud AUTHIER-REVUZ, 2004, p. 67).

A noção de sujeito assujeitado ao inconsciente - da psicanálise -, bem como assujeitado pela ideologia - das teorias do discurso que postulam a determinação histórica em um sentido não individual - a que nos referimos até aqui, constituiu uma perspectiva crucial para nossa concepção sobre a hesitação. Relacionada à negociação com os outros do discurso, a hesitação não configuraria um acontecimento consciente - no sentido de uma estratégia arquitetada pelo sujeito. Diferentemente, a ocorrência da hesitação seria indício, no discurso, da determinação do sujeito pelo inconsciente e pela ideologia - que mencionamos, em relação à contribuição do dialogismo do círculo de Bakhtin, como processo de constituição do sujeito.

Pelo exposto, a hesitação, ou, como preferimos, o acontecimento discursivo da hesitação, é um elemento da complexidade enunciativa, o que nos permitiu relacioná-lo às perspectivas teóricas que deram base para a proposição das heterogeneidades enunciativas. Salientemos que, embora essas perspectivas tenham contribuído para o amadurecimento de nossa concepção sobre a hesitação, foi a proposta de Authier-Revuz (1990) sobre a heterogeneidade mostrada no discurso que inspirou nossa proposição de que as marcas da hesitação indiciam momentos em que a negociação com os outros constitutivos do discurso estaria sendo problemática para o sujeito. Buscaremos, a partir deste ponto, situar a hesitação em relação aos tipos de heterogeneidade delineados por Authier-Revuz.

A partir da articulação entre (1) a concepção de sujeito e de sua relação com a linguagem, advinda da psicanálise, (2) o dialogismo como propriedade da linguagem, concepção advinda do círculo de Bakhtin, e (3) a concepção do discurso como produto do interdiscurso, advinda da Análise do Discurso, AuthierRevuz (1990, 2004) institui que "todo discurso se mostra constitutivamente atravessado pelos outros discursos [referindo-se, aí, à orientação dialógica do discurso e à sua determinação histórica] e pelo discurso do Outro [aqui, colocando em foco o sujeito-efeito, assujeitado ao inconsciente e assujeitado pela ideologia]" (p. 69). Essa seria a proposição geral a partir da qual a autora delimita duas ordens: a heterogeneidade constitutiva do discurso e a heterogeneidade mostrada no discurso.

É a proposição de que, no discurso, em toda parte, as palavras dos outros estão sempre presentes que define o que Authier-Revuz (1990, 2001, 2004) chama de heterogeneidade constitutiva do discurso. Segundo a autora, este tipo de heterogeneidade representa a ordem dos processos de constituição do discurso, em oposição à ordem dos processos de representação, num discurso, de sua constituição.

$\mathrm{O}$ que permite diferenciar a heterogeneidade constitutiva do discurso da heterogeneidade mostrada é o fato de que nem sempre a alteridade dos outros 
NASCIMENTO - Uma visão enunciativo-discursiva...

constitutivos do discurso está especificada na cadeia discursiva. Haveria, pois: (1) uma heterogeneidade "interna" ao sujeito e ao discurso e não diretamente localizável na estrutura formal que o constitui enquanto tal - a heterogeneidade constitutiva do discurso; e (2) outra que pressupõe a representação, no discurso, das fronteiras "interior/exterior" pelas quais um sujeito/um discurso se delimitaria na pluralidade dos outros, ou seja, a heterogeneidade mostrada no discurso. É a partir desses conceitos que Authier-Revuz propõe uma discussão sobre as formas de representação da heterogeneidade constitutiva, ou seja, sobre a heterogeneidade mostrada no discurso:

ao nível da cadeia do discurso, localizar um ponto de heterogeneidade é circunscrever este ponto, ou seja, opô-lo, por diferença do resto da cadeia, à homogeneidade ou à unicidade da língua, do discurso, do sentido, etc; corpo estranho delimitado, o fragmento marcado recebe nitidamente através das glosas de correção, reserva, hesitação... um caráter de particularidade acidental, de defeito local (1990, p. 31).

Assim, as formas (glosas de correção, hesitação ${ }^{8}$, retoque, ajustamento) que designam o outro na sequência do discurso seriam reflexos de uma atividade de "controle e regulagem" do processo de enunciação, sinal da falta ou do ajustamento, especificando as condições que o sujeito, sob sua tendência à ilusão do centro, vê como necessárias para que haja uma troca verbal percebida como normal. Vistas de outro modo, essas formas explícitas da heterogeneidade seriam pontos da negociação, obrigatória, do sujeito/do discurso com os outros que lhe são constitutivos, ou seja, uma espécie de manifestação dos diversos tipos de negociação do sujeito com a heterogeneidade constitutiva - com os outros da interlocução, com os outros sentidos, com os outros discursos.

Nesse viéséque tomamos a ocorrência da hesitação como indício danegociação do sujeito com os múltiplos outros constitutivos do (seu) discurso, negociação empreendida como tentativa9 ${ }^{9}$ de organizar o deslizamento, a instabilidade dos significantes. Remetemos, pois, a hesitação à noção de heterogeneidade mostrada, uma vez que ambas delatariam o mecanismo de organizar (segundo regras, não prescritivas) recortes, mobilizados do inconsciente, de outros que o constituem o sujeito.

8. Suspeitamos que o que Authier-Revuz entende por hesitação não se refere ao acontecimento discursivo que este artigo busca embasar/aprofundar. Tratando das formas marcadas de conotação autonímica, a autora (2004) parece entender hesitação como marca de uma atividade aparentemente bem sucedida de controle-regulagem cuja operação de ajuste se mostra como "X, enfim X, se quisermos, se assim se pode dizer, se for possível falar de 'X' em..." (p. 15). Diferentemente, a hesitação de que estamos tratando aqui constitui uma "tentativa de controle-regulagem" do discurso e se marca, não como uma operação de ajuste, mas como uma turbulência no/do discurso.

9. Destacamos essa palavra porque ela é a marca da distância entre as marcas de heterogeneidade mostrada privilegiadas por Authier-Revuz em seus trabalhos (1990, 2001, 2004, 2007), que ela denomina de modalidade autonímica, e a hesitação. Enquanto a modalidade autonímica apresenta-se sob o efeito de uma operação de ajustamento, digamos, bem sucedido, o efeito da representação da hesitação no discurso é o de um problema que pode, ou não, ser "contornado de modo bem sucedido". 
Cadernos de Estudos Lingǘlsticos (54.1) - Jan./Jun. 2012

Salientamos, assim, que a oposição heterogeneidade constitutiva do discurso e heterogeneidade mostrada no discurso reúne boa parte das observações que tomamos como ponto de partida da concepção de hesitação que esquematizaremos a seguir.

\section{UMA PROPOSTA ENUNCIATIVO-DISCURSIVA SOBRE A HESITAÇAO}

Conforme a discussão que propusemos até aqui, nossa formulação teórica sobre a hesitação pode ser sintetizada da seguinte forma: a hesitação constitui um acontecimento discursivo cujas marcas são indícios do processo de negociação do sujeito com os outros constitutivos do discurso/do sujeito. Passemos, com base na análise de um recorte de situação enunciativo-discursiva ${ }^{10}$, a delinear contribuições dessa formulação para a compreensão da hesitação.

\section{Recorte:}

$1 \mathbf{L Z}$ a T. é mineira e o senhor?

2 JP sou de Colina

3 LZ Colina?

4 JP São Paulo

5 LZ fica perto da onde?

6 JP $\underline{\text { m: : ais perto de: }}$ Barretos + + Bebedouro

Nesse recorte, tomamos a representação da hesitação no discurso - ou seja, a materialização dos alongamentos e da pausa silenciosa sublinhados na linha 6 -, como indício da tensão entre "mais perto de Colina" e "perto de Colina"; "Barretos" e "Bebedouro". Assim, detectamos mais de um significante, mais de um efeito de sentido concorrendo para ocupar um lugar na cadeia enunciativodiscursiva.

Nas linhas 5 e 6 emerge, na cadeia significante, um lugar lingüísticodiscursivo que descreve uma relação de distância com Colina. Especificamente em JP (linha 6), a emergência desse lugar se dá sob uma tensão (percebida, devido à ocorrência da marca de hesitação, como uma espécie de conflito) entre sentidos/ significantes depreendidos do enunciado da linha 5 ("fica perto da onde?") e sentidos/significantes outros que também atravessam o sujeito (sendo um deles

10. O recorte que apresentamos constitui parte de uma das amostras de conversação coletadas para o projeto Atividade discursiva oral e escrita de parkinsonianos: formação de um banco de dados. O objetivo mais específico desse projeto foi obter material para possibilitar pesquisas sobre aspectos discursivos na linguagem em sujeitos com doença de Parkinson. Entretanto, nosso foco no presente artigo constitui a hesitação, de forma que não nos ocupamos em destacar aspectos subjacentes à possível especificidade do contexto patológico do dado. 
manifesto como "mais perto de ..."). Tal tensão nos parece marcar, no que seria um movimento de "seleção" de um elemento lingüístico-discursivo a tomar lugar na cadeia significante, a "necessidade de" coordenação entre "a distância até Colina" e "as várias cidades próximas de Colina". A ocorrência da marca de hesitação - do alongamento - exatamente no primeiro elemento fonético-fonológico do significante que sinaliza de modo mais explícito essa coordenação entre "distâncias" e "cidades" (m::ais) que atravessa JP é um indício de tensão e, ao mesmo tempo, do movimento de negociação com os outros a que está submetido o sujeito.

Nesse caso específico, os outros em tensão com os quais o sujeito negocia seriam, pelo menos, dentre outros não alcançáveis: Colina fica perto de outra cidade ("Colina fica perto de onde?") versus Colina fica perto de várias cidades e mais perto de uma ou outra dessas várias cidades ("Colina fica mais perto de onde?").

Por outro lado, nessa mesma linha 6 do recorte, o lugar de cidade mais perto de Colina que emerge em JP deixa ver a concorrência entre os significantes "Barretos" e "Bebedouro" - dentre outros significantes/significados que, supostamente, atravessam JP. Afirmamos isso, baseados tanto na sequência de materialização linguística em que esses significantes aparecem quanto na característica prosódica de sua enunciação oral. O significante Barretos é pronunciado com abaixamento de frequência e de intensidade ao final da palavra, contorno típico de finalização de enunciado. Além disso, é seguido de uma pausa silenciosa, acontecimento amplamente descrito na literatura linguística como um dos sinalizadores de final de enunciado. "Bebedouro", por outro lado, emerge após essa primeira escolha de "cidade mais perto de Colina" e após uma pausa percebida como longa, fato que nos permitiu interpretar esse significante como uma opção em substituição a "Barretos". É justamente a ocorrência das marcas de hesitação - do alongamento em "de" e da pausa longa - antes e após a emergência de um primeiro significante e antes de sua suposta rejeição em favor de outro significante, que tomamos como indício do estatuto de momento de negociação com os outros constitutivos do sujeito que propomos como definidor da hesitação. No caso, podemos interpretar o alongamento como indício da tensão/negociação entre possíveis cidades a emergir no lugar de "cidade mais perto de Colina", tensão/ negociação que se detecta como mais explícita devido à materialização de duas dessas cidades - possivelmente cidades que JP presume como mais conhecidas de LZ, entre outros fatores concorrentes à situação enunciativa. A presença da pausa longa após "Barretos", por sua vez, indicia a tensão entre "duas cidades específicas, ambas perto de Colina": "Barretos", que já havia se materializado na cadeia discursiva, e "Bebedouro", significante que emerge nesse (que seria o) mesmo lugar da cadeia discursiva. Especialmente a emergência de "Bebedouro" em substituição a "Barretos" para o lugar de "cidade mais perto de Colina" chama nossa atenção, porque, enquanto Bebedouro está a aproximadamente $32 \mathrm{~km}$ (trinta e dois quilômetros) de Colina, Barretos está a aproximadamente $21 \mathrm{~km}$ (vinte e um quilômetros) de Colina. Esse último dado permite-nos pensar que a pausa longa de que vínhamos falando sinaliza não somente a concorrrência entre dois 
significantes com características fonético-fonológicas e semânticas semelhantes, mas também possivelmente o conflito entre duas experiências de vida do sujeito único fato que pudemos levantar como explicação para a "seleção" da cidade mais distante (entre as duas opções materializadas) para ocupar o lugar de "cidade mais perto de Colina".

Note-se que esse recorte é particularmente esclarecedor da nossa concepção sobre a hesitação porque os alongamentos e a pausa, além de indiciarem a negociação entre outros constitutivos do sujeito, apontaram para outros que se materializaram no processo discursivo, fato que nem sempre acontece ${ }^{11}$. Assim, a materialização desses outros nesse recorte fornece elementos para nossa consideração de que as marcas de hesitação são indícios da condição de clivado do sujeito, bem como indícios de uma tentativa do sujeito (centrado) de manter o efeito de homogeneidade do (seu) dizer. Segundo nossa interpretação, sob o efeito de ilusão de centro (do sujeito) esse sujeito se ancora em momentos como os de hesitação na tentativa de manter o efeito ilusório de unidade (do discurso). O fato dos efeitos de centro (do sujeito) e de unidade (do discurso) não terem sido bem sucedidos no recorte permite alçar, conforme levantamos na discussão sobre os subsídios teóricos, que no cerne da hesitação estariam mecanismos discursivos específicos que tornam possível uma cadeia discursiva. Entre esses mecanismos, destacamos (1) a constituição heterogênea do sujeito e do discurso e (2) o imaginário de um sujeito centrado (o "eu", ou, o sujeito linguístico) e de um discurso homogêneo (unidade ilusória de um discurso).

Levando em consideração a constituição heterogênea do sujeito e do discurso - (1) acima -, remetemos o discurso à possibilidade de a sequência de enunciados que o compõem ser linguisticamente descritível como pontos de deriva possíveis. Nesse viés, a hesitação é um acontecimento discursivo relacionado à deriva: sua representação no discurso indicia essa possibilidade incessante do dizer vir a ser outro, o que pode, ou não, se concretizar. No recorte que analisamos, essa possibilidade, em alguma medida, se efetiva - a deriva aparece no discurso. Observe-se que, conforme a análise apresentada, "mais perto" se materializa como outra possibilidade de relação entre Bebedouro/Barretos e Colina, e "Bebedouro" se materializa em substituição a "Barretos". Assim, a materialização de "mais perto" e de "Bebedouro", constitui uma marca da possibilidade incessante de significantes de um suposto conjunto de "distâncias" e de "cidades" estar em concorrência para um "único" lugar da cadeia significante. A ocorrência do alongamento em "mais" e em "de" e da pausa longa entre "Barretos" e "Bebedouro" sinaliza essa concorrência, ou seja, sinaliza a possibilidade do significante ser outro.

Tendo em vista as representações ${ }^{12}$ que engendram uma sequência discursiva - aquelas a que nos referimos em (2) como discurso homogêneo e sujeito centrado -, ponderamos que a hesitação é um acontecimento discursivo relacionado ao

11. Cf. Nascimento (2005 e 2010).

12. Referimo-nos, neste ponto, à série de formações imaginárias que, segundo Pêcheux (1997-a), designam o lugar que os sujeitos ("locutor" e "alocutário") atribuem cada um a si, ao outro, ao objeto do discurso; estes determinados por sua constituição histórica, social e, a nosso ver, também psíquica. 
NASCIMENTO - Uma visão enunciativo-discursiva...

processo de ancoragem: sua representação no discurso corresponderia ao que Tfouni (2005) qualifica como pontos em que o sujeito detém-se para conter a deriva sempre prestes a se instalar; pontos em que o sujeito, frente a agitações em suas filiações sócio-históricas de identificação, se apóia visando organizar, segundo regras não prescritivas, recortes (mobilizados de seu inconsciente) dos outros que lhe são constitutivos. Dito de outro modo, as marcas de hesitação constituem indícios da tomada de posição do sujeito em pontos em que, atrelando-se à matéria linguística, essa posição-sujeito ${ }^{13}$ coloca fronteiras entre o que é selecionado e o que é rejeitado, buscando sustentar um efeito de homogeneidade do (seu) dizer. Os alongamentos e a pausa do recorte que trouxemos são representativos desse movimento em que o sujeito, ancorado na cadeia significante (pensamos, na marca de hesitação), estabelece fronteiras para o discurso. Entretanto, especialmente a seleção de "Barretos" e, na sequência, de "Bebedouro" - dito de outro modo, a rejeição de "Barretos" em favor de "Bebedouro" - impede, ainda que momentaneamente, o "pretendido" efeito de unidade da cadeia significante.

\section{CONSIDERAÇÕES FINAIS}

Tomamos o discurso como uma série de pontos de deriva possíveis (PÊCHEUX, 2008). Entendemos que o sujeito ocupa um lugar (ou assume uma posição) que visa garantir o efeito de coesão e coerência do discurso (TFOUNI, 2005) - que referimos como efeito de homogeneidade/unidade do dizer. Dessa forma, não é sem tensões ou turbulências que o sujeito busca, de modo incessante, "conter" a deriva, "produzir" um discurso aparentemente homogêneo e "garantir" sua ilusão de sujeito centrado. No recorte que trabalhamos o efeito dos alongamentos e da pausa, conforme nossa escuta, é o de um defeito local. A escuta desse efeito permite-nos defender que a representação da hesitação no discurso constitui, como levantamos durante a análise do recorte, indício de tensões e de conflitos que caracterizam o processo de produção do discurso tensões que, no recorte, foram detectadas entre distâncias até Colina, duas cidades, cidades próximas de Colina, dois nomes cujas características fonético-fonológicas e semânticas se aproximam, e, possivelmente, entre as experiências de vida do sujeito. Nesse sentido, a hesitação seria um acontecimento que indicia, no discurso, quão problemático está sendo/é para o sujeito o processo de estabelecimento de fronteiras entre o "dito" e o "não-dito" que o constitui.

Conforme buscamos mostrar, a consideração da hesitação como acontecimento que indicia a negociação do sujeito com os outros constitutivos do discurso permite apreciar outros elementos que contribuem para uma delimitação enunciativo-discursiva desse fenômeno. Com base nessa formulação mais geral, vimos que a representação da hesitação no discurso constitui também indício

13. Remetemos essa posição sujeito ao "[...] efeito de um enunciador universal, que fala de um mundo semanticamente estabilizado, onde não exist[iria] discordância” (TFOUNI, 2005, p. 8). 
de deriva e de ancoragem e denuncia quão problemático é, para o sujeito, o estabelecimento de fronteiras do/no discurso.

Acreditamos, com essa proposição sobre hesitação, ter lançado luz sobre sua investigação como um fenômeno de natureza lingüístico-discursiva. Ambicionamos, com isso, instigar pesquisas com esse viés teórico e começar a contribuir para preencher o que percebemos como uma lacuna nos estudos brasileiros sobre hesitação.

\section{REFERÊNCIAS BIBLIOGRÁFICAS}

AUTHIER-REVUZ, J. (2004). Entre a transparência e a opacidade: um estudo enunciativo do sentido. Tradução de Marlene Teixeira. Revisão de Leci Borges Barbisan e Valdir do Nascimento Flores. Porto Alegre: EDIPUCRS.

. (1990). Heterogeneidade(s) enunciativa(s). Caderno de Estudos Lingüísticos, Campinas, v. 19, p. $25-42$.

BARROS, D. L. ( 1999). Pessoa de. Procedimentos e recursos discursivos da conversação. In. PRETI, D. (Org) Estudos da lingua falada: variações e confrontos. $2^{\mathrm{a}}$ Ed. São Paulo: Humanitas FFLCH/ USP, Cap. 2.

BAKHTIN, M. M. (2000). Os gêneros do discurso. In: Estética da criação verbal. 3. ed. Tradução de Maria Ermantina Galvão. Revisão Marina Appenzeller. São Paulo: Martins Fontes, Cap. 3.

COURTINE, J. J. (1999). O chapéu de Clémentis. Observações sobre a memória e o esquecimento na enunciação do discurso político. Os múltiplos territórios da Análise do Discurso, v. 12, p. 15-22.

FERRAZ E FERRAZ, M. da G. C. (2001). Noções básicas de psicanálise freudiana. In: Sujeito psíquico e sujeito linguístico: uma introdução à psicopatologia aplicada à fonoaudiologia. Marília: Unesp-Marília-Publicações, Cap. 1.

MARCUSCHI, L. A. (2006). Fenômenos Intrínsecos da Oralidade: a hesitação. In: KOCH, Ingedore Grunfeld Villaça; JUBRAN, Clélia C. A. Spinardi. Gramática do português falado: construção do texto falado. Campinas, SP: Editora da Unicamp. . (1999). A hesitação. In: NEVES, M. H. M. Gramática do Português Falado: novos estudos. Campinas: UNICAMP/FAPESP, p. 159-194. . (1998). Análise da conversação. 5. ed. São Paulo: Ática.

NASCIMENTO, J. C. (2010). Uma perspectiva discursiva sobre a hesitação. 305f. 2010. Tese (Doutorado em Estudos Lingüísticos) - Instituto de Biociências, Letras e Ciências Exatas, Universidade Estadual Paulista "Júlio de Mesquita Filho", São José do Rio Preto. (2005). Fenômeno hesitativo na linguagem: um olhar para a doença de Parkinson. 158f. 2005. Dissertação (Mestrado em Linguística) - Instituto de Biociências, Letras e Ciências Exatas, Universidade Estadual Paulista "Júlio de Mesquita Filho", São José do Rio Preto.

PÊCHEUX, M. (2008). O discurso: estrutura ou acontecimento. $5^{\mathrm{a}}$ ed. Tradução de Eni Pulcinelli Orlandi. São Paulo: Pontes.

. (1997a) Análise automática do discurso. In: GADET, Françoise; HAK, Tony. (Org.). Por uma análise automática do discurso: uma introdução à obra de Michel Pêcheux. Tradução de Bethânia S. Mariani et al. 3. ed. Campinas: Editora da Unicamp, Cap. 3. 
NASCIMENTO - Uma visão enunciativo-discursiva...

(1997b). A propósito da análise automática do discurso: atualização e perspectivas. In: GADET, Françoise; HAK, Tony. (Org.). Por uma análise automática do discurso: uma introdução à obra de Michel Pêcheux. Tradução de Bethânia S. Mariani et al. 3. ed. Campinas: Editora da Unicamp, Cap. 4.

TFOUNI, L. V. (2005). Letramento e autoria: uma proposta para contornar a dicotomia oral e escrita. Revista da ANPOLL, Campinas, n. 18, p. 127-141.

TFOUNI, F. E. V. (1998). O interdito como fundador do discurso. 1998, 115f. Dissertação (Mestrado em Linguística) - Universidade Estadual de Campinas, Instituto de Estudos da Linguagem, Campinas. 